\title{
Tabaquismo en Chile. Diagnóstico confirmado: tiempo de actuar
}

\author{
Tobacco epidemics in Chile: time for action
}

Para ejemplificar lo complejo que resulta abordar integralmente el cuidado de salud de la comunidad se suele recurrir al ejemplo de la labor de un salvavidas. En efecto, un buen salvavidas es aquel que tiene buenas destrezas para socorrer a un bañista en peligro de morir ahogado producto ya sea de su propio descuido o por acciones fortuitas que escapan de su control. No termina aquí la labor del salvavidas. Con la misma energía, éste debe procurar informar e instruir a los bañistas acerca de los cuidados que deben considerarse para no correr peligro en sus incursiones en el agua.

Es un salvavidas incompleto aquel que sólo se limita a socorrer al bañista, descuidando evitar que ellos incurran en situaciones de riesgo.

En cierta medida, esta imagen retrata con crudeza la paradójica situación chilena en relación con los cuidados de la salud y el consumo de tabaco.

Por largo tiempo, conocemos de la importante penetración del tabaco en nuestra población. Sucesivos informes y estudios, nos recuerdan insistentemente de esta situación, que no respeta edad, sexo ni posición social. Esta situación parece ser también, impermeable a la experiencia internacional y a las recomendaciones de organismos de salud ${ }^{1-4}$.

Chile cuenta con abundante evidencia local que indica una situación extremadamente alarmante respecto del consumo de tabaco. Inicio precoz del consumo, tabaquismo durante el embarazo, persistencia del hábito hasta edades avanzadas en la vida, inadmisibles tasas de exposición involuntaria al humo de tabaco son todas evidencias recientes de lo anterior ${ }^{2}$. Entre los años 2003 y 2010, la prevalencia nacional de tabaquismo no se ha modificado, la brecha existente entre fumadores y fumadoras se estrecha y lejos de disminuir, el consumo medio de cigarrillos entre los fumadores, éste aumenta. Estimamos además que el 9\% de la población chilena tiene algún grado de dependencia a la nicotina y no se logró cumplir con las metas propuestas en nuestros objetivos sanitarios 2000-2010 .

Es imposible seguir escondiendo la cabeza frente al problema y a este fracaso. En igual período, diversos países latinoamericanos (Argentina, Uruguay, México, Brasil, Bolivia, entre otros) y los Estados Unidos redujeron significativamente sus tasas de tabaquismo ${ }^{6,7}$. Paralelamente, en los Estados Unidos, el control del tabaquismo figuró entre los 10 principales logros en salud del siglo $X X^{8}$. Estos países, y muchísimos otros más, modificaron y mejoraron su legislación sobre el tabaco. Chile, también lo hizo (2006) ${ }^{9}$, con magros resultados.

Con certeza de maestro el Dr. Victorino Farga denuncia nuestra pasividad como profesionales en relación a este tema ${ }^{10}$, el cual explica con creces más de la mitad de la denominada "carga de enfermedad". Muerte y sufrimiento evitable, gasto de recursos que pudieran ser canalizados a atender nichos desatendidos en patología respiratoria, son apenas pálidos ejemplos de las consecuencias de la falta de control del tabaquismo en nuestro país.

Es tiempo de reaccionar organizadamente y por cierto, constituye también un imperativo ético comprometerse con la lucha antitabaco. Será preciso resistir los conocidos argumentos que se esgrimen cuando este tema se afronta como compromiso país con seriedad.

De nuestras autoridades se debe exigir un compromiso decidido, manifestado en el diseño de políticas públicas, abogacía y gestión de marcos legales, formulados adecuadamente. Chile ya vivió el desgastante proceso de modificar tibiamente su ley de tabaco (2006), obteniendo resultados proporcionales a la calidad de la ley finalmente aprobada por nuestros parlamentarios. Es preciso aprender de los errores, como también lo hizo España ${ }^{11,12}$.

A quienes desde esta Sociedad les compete la noble misión de tratar enfermos, les pedimos profundizar su sensibilidad frente al tema. En nuestras actividades científicas y de extensión nos gustaría ver atiborrados los salones con profesionales asistiendo a las instancias de capacitación y difusión sobre tabaco. La identificación del fumador, su orientación, apoyo, acompañamiento, tratamiento y 
seguimiento son acciones propias del cuidado clínico para las cuales hay que adquirir capacitación. Nuestros estudios al respecto sugieren que no lo estamos haciendo bien, dejando escapar oportunidades de intervención.

Paradójicamente muchos miembros de esta Sociedad son precisamente referentes nacionales en el tema, investigando y aportando localmente con valiosa información para la acción clínica.

En la lucha antitabaco hay algo más que intuición; la sustentan sólidas bases teóricas sobre aspectos conductuales y de dependencia a la nicotina que son de relativa fácil comprensión e indispensables para intervenir eficazmente.

La Sociedad Chilena de Enfermedades Respiratorias apoya y participa activamente en la actual modificación de nuestra legislación. Junto con otros grupos de la sociedad civil, adquirió el compromiso de requerir de la autoridad y de los legisladores la generación de cambios adecuados en esta modificación. De igual forma, se hace presente el pleno convencimiento de incrementar el impuesto al tabaco, como es la recomendación universal. La consideración de otorgar apoyo al fumador dependiente de la nicotina es también un elemento indispensable a juicio de esta Sociedad y ha sido planteado a las autoridades de salud de esta forma.

Las intervenciones exitosas en salud se construyen articulando tanto cambios estructurales (políticas y planes de salud), como acciones individuales (intervenciones clínicas), estrategia de antigua data ${ }^{13}$.

No es objetivo de esta Sociedad la dictación de Políticas de salud. No obstante, sí lo es promover que su diseño esté a la altura de las necesidades del país, especialmente, en su área de competencia.

En consecuencia, la invitación es a cumplir con las nobles tareas de todo buen salvavidas: tratar y cuidar adecuadamente la salud de nuestros pacientes desde esta especialidad y participar con compromiso en aquellas iniciativas destinadas a la prevención de las enfermedades respiratorias.

Dr. Gonzalo Valdivia C. Coordinador Comisión de Tabaquismo Miembro Comisión Científica

Sociedad Chilena de Enfermedades Respiratorias

\section{Bibliografía}

1. Primera Encuesta Nacional de Salud 2003. Resumen ejecutivo. Disponible en: http://epi.minsal.cl/epi/html/ elvigia/VIGIA20.pdf. Consultado el 12 de septiembre de 2011.

2. Segunda Encuesta Nacional de Salud 2009. Capítulo Resultados. Disponible en: http://www.minsal.gob.cl/ portal/docs/page/minsalcl/g_home/submenu_portada_2011/ens2010.pdf. Consultado el 12 de septiembre de 2011.

3. CONACE. Serie de estudios drogas y alcohol. Disponible en : http://www.senda.gob.cl/observatorio/estadisticas/poblacion-general/ Consultado el 12 de septiembre de 2011.

4. Encuesta mundial de tabaquismo en jóvenes. Website Depto. Epidemiología, MINSAL, Chile. Disponible en: http://epi.minsal.cl/epi/html/invest/EMTA/emta.htm Consultado el 10 de septiembre de 2011.

5. Objetivos sanitarios para la década 2000-2010. Depto. Epidemiología, MINSAL, Chile. Disponible en: http:// epi.minsal.cl/epi/html/elvigia/vigia15.pdf Consultado el 10 de septiembre de 2010.

6. Global Health Observatory Data Repository. OMS. http://apps.who.int/ghodata/?vid=1801\# Consultado el 10 de septiembre de 2011.

7. MÉNDEZ D, WARNER K. Adults cigarette smoking prevalence: declining as expected Am J Public Health 2004; 94: 251-2.

8. Ten Great Public Health Achievements - United States, 2001-2010 MMWR 2011; 60 (19): 619-23.

9. Ley No. 20.105 (Modifica la ley No. 19.419, en Materias relativas a la publicidad y el consumo del tabaco) 2006.

10. FARGA V. Conferencia Héctor Orrego Puelma 2010: "80 años de la Sociedad Chilena de Enfermedades Respiratorias: De la Tisiología a la Neumología pasando por la Medicina Interna”. Rev Chil Enf Respir 2011; 27: 31-3.

11. Ley $28 / 2005$, de 26 de diciembre, de medidas sanitarias frente al tabaquismo y reguladora de la venta, el suministro, el consumo y la publicidad de los productos del tabaco. Real decreto. Disponible en: http://www.boe.es/ boe/dias/2006/02/11/pdfs/A05436-05438.pdf Consultado el 9 de septiembre de 2011-09-14.

12. Ley $42 / 2010$, de 30 de diciembre, que modifica la Ley $28 / 2005$, de medidas sanitarias frente al tabaquismo y reguladora de la venta, el suministro, el consumo y la publicidad de los productos del tabaco. Disponible en http://www.boe.es/boe/dias/2010/12/31/pdfs/ BOE-A-2010-20138.pdf Consultado el 9 de septiembre de 2011.

13. ROSE G. Sick individuals and sick populations. Int. J. Epidemiol 2001; 30: 427-32. http://ije.oxfordjournals. org/content/30/3/427.full 